\title{
Title: Genome-Wide Survey and Expression Analysis of NIN-Like Protein (NLP) Genes Reveals Its Potential Roles in the Response to Nutrition Deficiency in Tomato
}

\author{
Mengyuan Liu \\ China Agricultural University \\ Xiaona Zhi \\ China Agricultural University \\ Yi Wang \\ China Agricultural University \\ Yang Wang ( $\square$ wangy@cau.edu.cn ) \\ China Agricultural University
}

\section{Research Article}

Keywords: NIN-Like Proteins, Tomato, Bioinformatics, Nitrate uptake, Nutrition deficiency

Posted Date: February 18th, 2021

DOI: https://doi.org/10.21203/rs.3.rs-199932/v1

License: (a) (i) This work is licensed under a Creative Commons Attribution 4.0 International License.

Read Full License

Version of Record: A version of this preprint was published at BMC Plant Biology on July 23rd, 2021. See the published version at https://doi.org/10.1186/s12870-021-03116-0. 


\section{Abstract}

Background: Tomato (Solanum lycopersicum) is one of the most important horticultural crops, with a marked preference of nitrate as inorganic nitrogen source. The molecular mechanisms of nitrate uptake and assimilation are poorly understood in tomato. NIN-Like Proteins (NLPS) are conserved, plant-specific transcription factors that play crucial roles in nitrate signaling.

Results: In this study, genome-wide analysis revealed six NLP members in tomato genome. They were clustered into three clades in a phylogenic tree. Comparative genomic analysis showed that SINLP genes had collinear relationships to NLPS in Arabidopsis, canola, maize and rice, and that the expansion of the SINLP family mainly resulted from segmental duplications in tomato genome. Tissue-specific expression analysis showed that the close homologues of $A t N L P 6 / 7, S I N L P 3$, was strongly expressed in roots during both seedling and flowering stages; SINLP4 and SINLP6 exhibited preferential expression in stems and leaves; and SINLP6 were expressed in high levels in fruits. Further, the nitrate uptake in tomato roots and expression patterns of SINLP genes were measured under nitrogen/phosphate/potassium deficiency and nitrate resupply conditions. The transcript abundance of SINLP3 decreased to $70 \%$ under phosphate/potassium deficiency. Most of SINLPS were up-regulated after nitrogen starvation. SINLP1 and $S / N L P 5$ were induced rapidly and temporally by nitrate.

Conclusions: These results provided significant insights into the potential diverse functions of SINLPS to regulate nitrate uptake.

\section{Background}

Nitrogen $(\mathrm{N})$, one of essential macro-nutrients for plants, serves as the component of amino acids, nucleotides, chlorophyll, hormones and co-enzymes. The growth and development of plants depends on proper nitrogen supply. And the availability of $\mathrm{N}$ in agricultural field affects crop yields significantly (Miller and Cramer, 2005). Plants absorb inorganic $\mathrm{N}$ from the soils mainly in two forms, nitrate $\left(\mathrm{NO}_{3}{ }^{-}\right)$and ammonium $\left(\mathrm{NH}_{4}{ }^{+}\right)$. Under mild climatic conditions, nitrate is the main nitrogen source in dry land (Forde and Clarkson, 1999). The concentration of nitrate in the soils fluctuates between $10 \mu \mathrm{M}$ to $100 \mathrm{mM}$ (Crawford, 1995). To sustain vigorous growth, high-affinity and low-affinity transport systems have been evolved in plants to absorb nitrate efficiently from the environment. Nitrate is also one of important signaling molecules for lateral root development, flowering and synergistic absorption of the other nutrients (Vidal et al., 2020).

For nitrate signaling, NIN-Like Proteins (NLPs) are identified as essential transcription factors (Konishi and Yanagisawa, 2013). It is reported that nutrient-Ca ${ }^{2+}{ }_{-}$NLP regulatory pathway plays the central role in nitrate signaling and integrates transcription, transport, metabolism and systemic growth programs in plants (Castaings et al., 2009; Marchive et al., 2013; Liu et al., 2017). In Arabidopsis, Nitrate tansporter 1.1 (NPF6.3/NRT1.1) has been identified as the nitrate sensor at the plasma membrane (Ho et al., 2009). In the presence of nitrate, calcium-dependent protein kinases 10/30/32 (CPK10/30/32) mediate $\mathrm{Ca}^{2+}$ 
signals by nitrate and phosphorylate NLP6/7 to ensure their location in the nucleus for transcriptional activation of the primary nitrate response genes (Liu et al., 2017).

NIN protein was firstly identified in legume Lotus japonicus, with regulatory function on symbiotic root nodule formation (Schauser et al.,1999). Then, more members of NIN proteins and NLPs were found widely existing among other non-leguminous plants including Arabidopsis, rice, wheat, and maize, but not in animals (Schauser et al., 2005; Kumar et al., 2018; Wang et al., 2018; Mu and Luo, 2019). Both NIN proteins and NLPs have RWP-RK domain for DNA binding; NLPs carry an additional PB1 domain for protein-protein interaction (Chardin et al., 2014). Interactions between NLPs and other transcription factors such as nitrate regulatory gene 2 (NRG2) (Xu et al., 2016), PCF (TCP)-domain family protein 20 (TCP20) (Guan et al., 2017), and nitrate-inducible GARP-type transcriptional repressor 1 (NIGT1) (Meada et al., 2018) have been reported. Beyond nitrate signaling, extra functions of NLPs in the N starvation response (Guan et al., 2017), N and phosphate (P) interactions (Meada et al., 2018), nitrate-promoted seed germination (Yan et al., 2016), nitrate-dependent nodule symbiosis (Nishida et al., 2018) and root cap cell release (Karve et al., 2016) have been clarified.

As one of the most important crops, tomato (Solanum lycopersicum) shows a marked preference of nitrate as inorganic nitrogen source (Errebhi et al., 1990).

In the present study, comparative bioinformatics analysis of the tomato NLPgenes was performed. Further, the rate of root nitrate uptake and expressions of SINLP genes under nutrition deficiency and nitrate resupply conditions were detected to evaluate their potential roles in nitrate uptake regulation in roots.

\section{Results}

\section{Identification of NLPGenes in tomato}

Table 1. Identification of NLP Genes in tomato

\begin{tabular}{|c|c|c|c|c|c|c|}
\hline $\begin{array}{l}\text { Gene } \\
\text { Name }\end{array}$ & Gene ID & $\begin{array}{l}\text { Protein } \\
\text { Characteristics }\end{array}$ & $\begin{array}{l}\text { Subcellular } \\
\text { localization }\end{array}$ & & & \\
\hline $\begin{array}{l}\text { Length } \\
\text { (aa) }\end{array}$ & $\mathrm{Mw}(\mathrm{Da})$ & $\mathrm{pl}$ & GRAVY & & & \\
\hline SINLP1 & Solyc01g112190.3 & 841 & 93298.51 & 7.35 & -0.524 & Nucleus/cytosol \\
\hline SINLP2 & Solyc04g082480.3 & 912 & 102467.99 & 5.58 & -0.520 & Nucleus/cytosol \\
\hline SINLP3 & Solyc08g008410.3 & 1008 & 109783.94 & 5.70 & -0.327 & Nucleus/cytosol \\
\hline SINLP4 & Solyc08g013900.3 & 961 & 106149.69 & 5.41 & -0.347 & Nucleus/cytosol \\
\hline SINLP5 & Solyc08g082750.3 & 1611 & 180948.88 & 6.16 & -0.473 & Nucleus/cytosol \\
\hline SINLP6 & Solyc11g045350.2 & 986 & 108349.29 & 5.30 & -0.416 & Nucleus/cytosol \\
\hline
\end{tabular}


Mw, molecular weight; pl, isoelectric point; GRAVY, grand average of hydropathicity.

A total of six NLPgenes were identified from tomato genome for presence of conserved RWP-RK (hmm, PF02042) and PB1 domains (hmm, PF00564). The nomenclature used for SINLP genes was based on their distribution on the chromosomes (Table 1). The numbers of amino acids coded by SINLP genes ranging from 841 (SINLP1) to 1611 (SINLP5). The relative molecular weights (Mw) were between 93.30 $\mathrm{kDa}$ (SINLP1) and $180.95 \mathrm{kDa}$ (SINLP5). All SINLP proteins had a isoelectric point near neutral (5.30$7.35)$, and low hydrophilicity indicated by GRAVY values $(-0.524$ to -0.327$)$. The subcellular localizations were predicted to be in the nucleus/cytosol for all six SINLPs.

\section{Conserved motifs and phylogenetic analysis of SINLP proteins}

Based on the previous study, Arabidopsis NLP proteins were divided into three clades (Schauser et al., 2005). To analyze the evolutionary relationship of tomato NLP proteins, a Neighbor-Joining phylogenetic tree was constructed by comparing tomato NLP amino acid sequences with NLPs from four other plant species, including two dicotyledonous plants (Arabidopsis and canola) and two monocotyledonous plants (rice and maize) (Supplementary Table 1). The result (Fig. 1A) showed that Clade I contained 17 NLP members, including AtNLP1/2/3/4/5 and SINLP1/2. Clade II contained 17 NLP members, including AtNLP6/7 and SINLP3/5. Clade III contained 31 NLP members, including AtNLP8/9 and SINLP4/6. Both dicotyledonous and monocotyledonous members existing in every clade indicated that gene expansion of the NLP gene family occurred before the ancestral divergence of monocotyledon and dicotyledon. The multiple sequence alignment (Fig. 1B and 1C) revealed all the NLP proteins share similar motif patterns, including the conserved RWP-RK domain and PB1 domain. Interestingly, SINLP5 protein appeared to carry double RWP-RK domains and PB1 domains.

\section{Chromosomal distribution and syntenic analysis of SINLP genes}

Six SINLP genes were distributed unevenly in tomato genome (Fig. 2). SINLP3, SINLP4 and SINLP5 were identified on chromosomes 8. The other three SINLP genes, SINLP1, SINLP2 and SINLP6 genes were identified on chromosomes 1, 4 and 11, respectively. Inter-chromosomal relationship of SINLP genes showed two pairs of segmental duplications (SINLP1 and SINLP2, SINLP3 and SINLP5), indicating that tomato NLPgenes were mainly generated by gene duplication during evolution.

Further, four comparative syntenic maps between tomato and Arabidopsis, canola, rice and maize, were constructed, to analyze the phylogenetic mechanisms of SINLPS (Fig. 3). Tomato SINLP genes showed 10 syntenic gene pairs with canola, 8 with Arabidopsis, 5 with maize and 3 with rice. Most background collinear blocks associated with NLP gene pairs identified between tomato and dicotyledon Arabidopsis/canola contained more genes than those between tomato and monocotyledon rice/maize (Supplementary Table 2). SINLP1, SINLP2 and SINLP5 were found in the four comparative syntenic maps, suggesting that these orthologous pairs might already exist before evolutional divergence of monocotyledon and dicotyledon, and these three genes might have played fundamental roles in NLP gene family. The ratio of non-synonymous (Ka) to synonymous substitutions (Ks), presenting the 
selection type acting on the coding sequences, were also calculated (Supplementary Table 2). Two SINLP gene pairs, SINLP1 and SINLP2, SINLP3 and SINLP5, had Ka/Ks ratio of 1.01 and 1.46, respectively, indicating positive selection during evolution for functional divergence occurring after duplication. Most of the orthologous NLP gene pairs had a Ka/Ks ratio less than 1 (ranging from 0.10 to 0.96 ), suggesting purifying selective pressure during NLP gene family evolution and conserved functions of these genes. Three orthologous gene pairs, SINLP1 and AtNLP5, SINLP2 and BnaNLP4-4, SINLP1 and ZmNLP1, had a $\mathrm{Ka} / \mathrm{Ks}$ ratio more than 1 , indicating they have underwent positive selection pressure and might be evolved with some new functions to cope with their living environments.

\section{Organ-dependent expression of SINLPS}

To obtain evidence of physiological function, tissue-specific transcript abundance of 6 SINLP genes was analyzed by qRT-PCR at different developmental stages (Fig. 4). All of SINLP genes had relatively low expression levels, $1 / 10000-4 / 100$ of the level of internal control SIEF1a gene expression. SINLP1 had the lowest expression. Therefore, SINLP1 expression levels in roots or fruits were set to 1 for comparison of expression levels. At both the seedling and flowering stages, SINLP2 and SINLP3 were preferentially expressed in roots (Fig. 4A and 4B). SINLP2 and SINLP3 showed the highest transcript abundance in root at the seedling stage (Fig. 4A). When flowering, SINLP3 still showed the most abundance in roots, followed by SINLP3 and SINLP6 (Fig. 4B). At the flowering stage, the transcript abundance of SINLP4 and SINLP6 increased significantly in all the test tissues, with preferential expression in stems and leaves. And SINLP6 had highest transcript accumulation in leaves, stems and flowers. Particularly, significantly higher expression of SINLP6 was observed in fruits (Fig. 4C).

\section{Expression of SINLPs in response to nutrition deficiency}

Nitrate absorption in tomato roots were found to be influenced by major mineral elements nutrition (nitrogen/phosphate/potassium) deficiency, indicated by ${ }^{15} \mathrm{NO}_{3}{ }^{\square}$ influx assay after different treatments (Fig. 5). The results showed that the root high-affinity nitrate uptake ability was enhanced under nitrogen starvation, but repressed under potassium/phosphate starvation (Fig. 5A). And the root low-affinity nitrate uptake ability was enhanced under potassium starvation, but repressed under nitrogen/phosphate starvation (Fig. 5B).

To obtain evidence of possible roles of SINLPs in root nitrate absorption regulation during nutrition deficiency, the transcript abundance of SINLP genes in roots was examined by qRT-PCR after starvation treatments (Fig. 6). The expression of SINLP1, SINLP2, SINLP4 and SINLP6 were up-regulated for 6.2, 3.1, 17 and 1.5 times, respectively, after nitrogen starvation. In response to phosphate starvation, SINLP3 showed expression decrease to $70 \%$ specifically. And the expression level of SINLP2, SINLP3 and SINLP6 decreased to around $70 \%$ in response to potassium starvation.

\section{Nitrate-dependent expression of SINLPS}


Both the root high-affinity and low-affinity nitrate uptake rates were enhanced after nitrate resupply to the nitrogen-starved plants, showed by results of ${ }^{15} \mathrm{NO}_{3}{ }^{\square}$ influx assay (Fig. 7). The nitrate-dependent expression of $S / N L P$ genes in roots were examined at $0.5 \mathrm{~h}, 1 \mathrm{~h}$ and $2 \mathrm{~h}$ after nitrate was resupplied to the starved seedlings. The results (Fig. 8) showed that the transcript abundance of SINLP1 and SINLP5 increased rapidly and temporally in response to nitrate. The expression of SINLP1 and SINLP5 reached the maximum levels, 4.1 and 2.8 times respectively, $0.5 \mathrm{~h}$ after nitrate was supplied. The expression of SINLP2 and SINLP4 was repressed significantly after nitrate resupply for $1 \mathrm{~h}$. By contrast, SINLP3 and SINLP6 did not show any response to nitrate in transcription level.

\section{Discussion}

In the present study, genome-wide analysis revealed six tomato NLPS (Table 1). The Solanum lycopersicumNLP family size is similar with Arabidopsis thaliana (9), Oryza sativa (5) and Zea mays (9), much smaller than Brassica napus (31). Phylogenetic analysis showed that every NLP family has members belongs to three groups (Fig. 1A). All of SINLPs has conversed RWP-RK and PB1 domains. SINLP5 is special for double RWP-RK and PB1 domains (Fig. 1B). The expansion of tomato NLPgene family was mainly generated by gene duplication in genome (Fig. 2). Orthologous gene pairs associated with $S I N L P 1, S I N L P 2$ or SINLP5 were indicated existence before the ancestral divergence of dicotyledonous and monocotyledonous plants (Fig. 3). It is worth noting that $\mathrm{Ka} / \mathrm{Ks}$ ratio of two paralogous SINLP gene pairs (SINLP1 and SINLP2, SINLP3 and SINLP5) and three orthologous NLP gene pairs (SINLP1 and AtNLP5, SINLP2 and BnaNLP4-4, SINLP1 and ZmNLP1) were more than 1 (Supplementary Table 2), representing positive selection and fast evolutionary rates in these SINLPs at the protein level. Therefore, it is implied that NLPs in tomato might evolve some new functions to meet their growth and development demands.

As one of fundamental regulatory elements at the transcriptional level, NLPs play important roles in nitrate uptake and assimilation regulation (Guan, 2017; Gaudinier et al., 2018). Tissue-dependent expression pattern showed that all 6 SINLP genes were expressed in all tested tissues including roots, stems, leaves, flowers and fruits (Fig. 4), which is similar with NLPs in Arabidopsis (Chardin et al., 2014), maize (Ge et al., 2018) and Brassica napus (Chardin et al., 2014). SINLP3, one of the close homologues of AtNLP6/7(Fig. 1A), the key component of nitrate signaling (Liu et al., 2017), has the highest expression level in roots at both seedling and flowering stages. Besides SINLP3, SINLP2 and SINLP6 were also expressed in high levels in roots, at different stages of development, implying their different functions in nitrate uptake regulation, rather than simple functional redundancy. Two SINLPS from Clade III, SINLP4 and $S I N L P 6$, showed preferentially expressed in aboveground tissues and were strongly up-regulated in their transcription abundance when flowering, suggesting that they might probably regulate nitrogen translocation and assimilation to support flower and fruit development. Different from SINLP4, SINLP6 had higher transcript abundance both in roots and aboveground tissues. What is more, SINLP6 showed extremely higher expression level than all the other five SINLPS in fruits. The close homologue of SINLP6 
is AtNLP8 (Fig. 1A). AtNLP8 has been reported as a master regulator of nitrate-promoted seed germination (Yan et al., 2016), which might provide some hints for functional research on SINLP6.

Nitrate is more favorable inorganic nitrogen source form for tomato. The nitrate uptake in tomato roots must be under precise regulation with complex interactions between nitrogen and the other essential macro-nutrients phosphate and/or potassium availability (Vidal et al., 2020). When environmental nitrogen source is depleted, the root low-affinity nitrate influx rate decreased, but high-affinity nitrate influx rate increased (Fig. 5). Similar results have been reported that higher nitrate influx was detected in tomatoes growing in nutrient solutions containing $5 \mathrm{mM}$ nitrate than $0.1 \mathrm{mM}$ (Abenavoli et al., 2016). Both low-affinity and high-affinity nitrate uptake in roots increased after nitrate was resupplied to the nitrogen-starved tomato seedlings (Fig. 7). Distinct from nitrogen starvation, potassium deficiency led to enhanced low-affinity nitrate influx rate and deceased high-affinity nitrate rate in roots (Fig. 5), which is reasonable because some published data show that strong expression increase of the nitrate transporters SINRT1.2 and SINRT2.1 had been induced by potassium deprivation (Wang et al., 2001). Slow-down of both low-affinity and high-affinity nitrate uptake rate were observed under phosphate deficiency (Fig. 5), which is consistent with the recent study in Arabidopsis (Wang et al., 2020).

In Arabidopsis, nlp7 mutants show features of a nitrogen-starved plant (Castaings et al., 2009); AtNLP7 overexpression increases plant biomass under both nitrogen-poor and -rich conditions (Yu et al., 2016). Expression of rice NLPs (OsNLP1, OsNLP4 and OsNLP5) was promoted by nitrogen deficiency as well as nitrate supply (Jagadhesan et al., 2020). Overexpression of OsNLP1 could enhance rice nitrogen use efficiency (Alfatih et al., 2020). Here, the transcript abundance of SINLPs in roots has been detected under various nutrition conditions (Fig. 6 and Fig. 8). Most of SINLPS (SINLP1, SINLP2,SINLP4 and SINLP6) showed up-regulated expression after nitrogen starvation for 2 days. When nitrate was resupplied, the temporal expression of SINLP2 and SINLP4 was repressed, but SINLP1 was still showed rapidly upregulated. One of the two close homologues of $A t N L P 6 / 7, S I N L P 5$, was induced rapidly and temporally by nitrate. However, the other close homologue of $A t N L P 6 / 7, S I N L P 3$, which showed the highest expression level in roots during both seedling and flowering stages (Fig. 4), did not show any response to nitrate. It is noteworthy that AtNLP6/7 responds to nitrate signaling not in transcription level either (Liu et al., 2017). Under phosphate deficiency or potassium deficiency, SINLP3 could be down-regulated in transcript abundance. After 2-days' phosphate starvation, SINLP3 was the only SINLP gene to show altered expression level, $70 \%$ of control. SINLP3 also showed decreased transcript abundance to $70 \%$ after potassium starvation for 2 days, together with another two SINLP genes, SINLP2 and SINLP6. Therefore, it is interesting to figure out how SINLP3 participate in various nutrition deficiency signaling and/or nitrate signaling pathways.

\section{Conclusions}

In summary, this study provided genome-wide analysis of $N L P$ genes in tomato. NLP genes are highly conserved among tomato, Arabidopsis, canola, maize and rice. Segmental duplication was the major driving force of SINLP genes evolution. Some SINLP genes had undergone positive selection during 
evolution, probably leading to functional divergence in gene family. The expression patterns of SINLP genes provided hints for their diverse physiological roles in tomato growth and development, especially in nitrate uptake regulation. Further functional analysis for each SINLP, especially SINLP3 and SINLP6, will be necessary to explore their regulatory functions. It is believed that a comprehensive understanding of the roles of SINLP under fluctuating nutrition conditions is an essential step towards deciphering the molecular mechanism of nitrogen utilization and promoting nitrogen use efficiency in tomato.

\section{Methods}

\section{Database search for NLP proteins}

Raw Hidden Markov Model (HMM) data of the conserved RWP-RK (PF02042) and PB1 (PF00564) domain downloaded from Pfam (http://pfam.xfam.org) (Finn et al., 2016) was used to search for their orthologs in the tomato genome (Solanum_lycopersicum.SL3.0), with e-value of less than $1 e-10$ in Phytozome (https://phytozome-next.jgi.doe.gov/info/Slycopersicum_ITAG2_4). Then, the results were confirmed by SMART (http://smart.embl.de/), NCBI Conserved Domains Database (CDD) (http://www.ncbi.nlm.nih.gov/cdd), and Plant Transcription Factor Database (TFDB) (http://planttfdb.cbi.pku.edu.cn/) database. The physicochemical properties of SINLP proteins, including peptide length (aa), molecular weight $(\mathrm{Mw})$, isoelectric point $(\mathrm{pl})$ and grand average of hydrophilicity (GRAVY) were predicted using ExPASy ProtParam (http://web.expasy.org/protparam/) (Gasteiger et al., 2005). Subcellular localizations of SINLP proteins were predicted using CropPAL2020 (https://www.croppal.org) (Hooper et al., 2020).

\section{Multiple sequences alignment and phylogenetic analysis}

Clustal W (version 2.1) was employed for the multiple sequences alignment and sequence identity matrix of the proteins (Larkin et al., 2007). Then, the deduced amino acid sequences in RWP-RK and PB1 domains were adjusted manually using GeneDoc software. Phylogenetic tree was constructed with MEGAX program (http://www.megasoftware.net/) using the Neighbor-Joining method. Proportions of amino acid differences were computed using Poisson correction distance to estimate evolutionary distance. The pairwise deletion option was used to circumvent the gaps and missing data. The conserved protein motifs of SINLP proteins were analyzed using MEME server v5.3.0 (http://memesuite.org/tools/meme) (Bailey et al., 2015). The parameters for the search were as follows: max motif number to find is 5 and min-max motif width to find is $2-40$. The matched motifs with low quality were manually removed based on an e-value of less than $1 e-15$. Sequences of NLP proteins of tomato (Solanum lycopersicum), Arabidopsis (Arabidopsis thaliana), canola (Brassica napus), rice (Oryza sativa) and maize (Zea mays) were downloaded from Phytozome (https://phytozome.jgi.doe.gov/).

\section{Chromosomal distribution and gene duplication}

All SINLP genes were mapped to chromosomes based on physical location information using Circos (Krzywinski et al., 2009). Then, chromosome distribution was plotted with MapChart2.0 
(https://mapchart.net/). The gene duplication events were analyzed using Multiple Collinearity Scan toolkit MCScanX. The syntenic analysis maps of orthologous NLP genes were constructed using the Dual Systeny Plotter software (https://github.com/CJ-Chen/TBtools) (Chen et al., 2020). Non-synonymous $(\mathrm{Ka})$ and synonymous $(\mathrm{Ks})$ substitution of each duplicated NLPgenes were calculated using KaKs_Calculator 2.0 (Wang et al., 2010).

\section{Plant materials and treatments}

Tomato ecotype Micro-Tom was used in this study. The seeds were germinated and grown on vermiculite for $7 \mathrm{~d}$ before transferred to hydroponics. The hydroponic minimal medium comprised $2 \mathrm{mM} \mathrm{KH}_{2} \mathrm{PO}_{4}, 2$ $\mathrm{mM} \mathrm{MgSO}_{4}, 25 \mu \mathrm{M} \mathrm{H}_{3} \mathrm{BO}_{3}, 2 \mu \mathrm{M} \mathrm{ZnSO}_{4}, 2 \mu \mathrm{M} \mathrm{MnCl}_{2}, 0.5 \mu \mathrm{M} \mathrm{CuSO}_{4}, 0.5 \mu \mathrm{M} \mathrm{Na}_{2} \mathrm{MoO}_{4}$, and $20 \mu \mathrm{M} \mathrm{Fe}-$ EDTA. This was supplemented with $1.3 \mathrm{mM} \mathrm{Ca}\left(\mathrm{NO}_{3}\right)_{2}, 1.5 \mathrm{mM} \mathrm{KNO}_{3}, 0.14 \mathrm{mM} \mathrm{KH}_{2} \mathrm{PO}_{4}$, and $1 \mathrm{mM}$ $\mathrm{MgSO}_{4}$ as normal condition. The $\mathrm{pH}$ of the solutions was maintained at approximately 5.8. Nutrient solutions were completely replaced weekly. Plants were grown at $28 / 22{ }^{\circ} \mathrm{C}$ with $16 / 8 \mathrm{~h}$ light/dark photoperiod. Plants grown in hydroponics for 4 weeks were used for nutrition deficiency treatments and nitrate treatment. For nitrogen starvation treatment $(\mathbb{V N})$, hydroponic minimal medium with $1 \mathrm{mM} \mathrm{CaCl}_{2}$, $0.6 \mathrm{mM} \mathrm{K}_{2} \mathrm{SO}_{4}, 0.25 \mathrm{mM} \mathrm{KH}_{2} \mathrm{PO}_{4}$, and $0.5 \mathrm{mM} \mathrm{MgSO}_{4}$ were used for 2 days. For phosphate starvation treatment $(\mathbb{P})$, hydroponic minimal medium with $2 \mathrm{mM} \mathrm{Ca}\left(\mathrm{NO}_{3}\right)_{2}, 0.35 \mathrm{mM} \mathrm{KCl}, 0.65 \mathrm{mM} \mathrm{K}_{2} \mathrm{SO}_{4}$ and 2 $\mathrm{mM} \mathrm{MgSO}_{4}$ were used for 2 days. For potassium starvation treatment $(\nabla \mathrm{K})$, hydroponic minimal medium with $2 \mathrm{mM} \mathrm{Ca}\left(\mathrm{NO}_{3}\right)_{2}, 0.25 \mathrm{mM} \mathrm{NaH}_{2} \mathrm{PO}_{4}$ and $1.4 \mathrm{mM} \mathrm{MgSO}_{4}$ were used for 2 days. For nitrate treatment, $\mathrm{N}$-starved plants were resupplied with $5 \mathrm{mM}$ nitrate medium (hydroponic minimal medium with $\mathrm{KNO}_{3}$ ) for indicated time.

\section{RNA extraction, cDNA synthesis, and qRT-PCR}

Total RNA of different tissues was extracted using M5 SuperPure Total RNA Extraction Reagent (Mei5 Biotechnology Co. Ltd). Then, the DNA-free RNA was used for synthesis cDNA by using RevertAid First Strand cDNA Synthesis Kit (Cat. No. K1622, Thermo). The quantitative RT-PCR (qRT-PCR) was performed using SYBR Green PCR Master Mix (Life Technologies) in 7500 Real-Time PCR System (Applied Biosystems). The house-keeping tomato EF1a gene (Solyc06g009970.3) was used as an internal control. Primer Sequences used qRT-PCR were listed in Supplementary Table 3.

\section{${ }^{15} \mathrm{NO}_{3}{ }^{-}$Uptake Assay}

${ }^{15} \mathrm{NO}_{3}{ }^{-}$influx in roots was determined as previously described (Zou et al., 2020). Tomato roots were washed in $\mathrm{CaSO}_{4}$ for $1 \mathrm{~min}$ and then submerged in medium containing $1 \mathrm{mM}$ or $0.1 \mathrm{mM} \mathrm{K}{ }^{15} \mathrm{NO}_{3}$ for 5 min. ${ }^{15} \mathrm{~N}$ concentration was measured using an isotope ratio mass spectrometer (IRMS; DELTA ${ }^{\text {plus }} \mathrm{XP}$ ).

\section{Statistical analysis}


Data were processed using the statistics program SPSS version 21. The statistical significance of differences in ${ }^{15} \mathrm{~N}$ influx and gene expression was examined by student's t-test $\left({ }^{\star} p<0.05\right.$, $\left.{ }^{\star \star} p<0.01\right)$.

\section{Declarations}

\section{Ethics approval and consent to participate}

The experimental research on plants performed in this study complies with institutional, national and international guidelines.

\section{Consent for publication}

Not applicable.

\section{Availability of data and materials}

The datasets used and/or analysed during the current study available from the corresponding author on reasonable request.

\section{Competing interests}

The authors declare that they have no competing interests.

\section{Funding}

This work was supported by grants from the National Natural Science Foundation of China (No. 31400222).

\section{Authors' contributions}

1. W. and M. L. designed the research plan and analyzed the data, M. L. performed the experiments, and X. Z. assisted in tomato hydroponics. The manuscript was written by Y. W.. Y. W. helped to revise the manuscript.

\section{Acknowledgements}

We thank Professor Jin Kong from China Agricultural University for donating tomato Micro-Tom seeds.

\section{Author Information}

Affiliations: State Key Laboratory of Plant Physiology and Biochemistry, College of Biological Sciences, China Agricultural University, Beijing 100193, China

Mengyuan Liu, Xiaona Zhi, Yi Wang, Yang Wang

Correspondence to Yang Wang wangy@cau.edu.cn 


\section{Supplementary Information}

Supplementary Table 1. NLP genes from tomato, Arabidopsis, canola, rice and maize.

Supplementary Table 2. One-to-one orthologous relationships between tomato and other four plant species.

Supplementary Table 3. Primers used in qRT-PCR.

\section{References}

Abenavoli MR, Longo C, Lupini A, Miller AJ, Araniti F, Mercati F, Princi MP, Sunseri F. Phenotyping two tomato genotypes with different nitrogen use efficiency. Plant Physiol Biochem. 2016;107:21-32.

Alfatih A, Wu J, Zhang ZS, Xia JQ, Jan SU, Yu LH, Xiang CB. Rice NIN-LIKE PROTEIN 1 rapidly responds to nitrogen deficiency and improves yield and nitrogen use efficiency. J Exp Bot. 2020;71:6032-42.

Bailey TL, Johnson J, Grant CE, Noble WS. The MEME Suite. Nucleic Acids Res. 2015;43:W39-49.

Castaings L, Camargo A, Pocholle D, Gaudon V, Texier Y, Boutet-Mercey S, Taconnat L, Renou JP, DanielVedele F, Fernandez E, Meyer C, Krapp A. The nodule inception-like protein 7 modulates nitrate sensing and metabolism in Arabidopsis. Plant J. 2009;57(3):426-35.

Chardin C, Girin T, Roudier F, Meyer C, Krapp A. The plant RWP-RK transcription factors: key regulators of nitrogen responses and of gametophyte development. J Exp Bot. 2014;65:5577-87.

Chen C, Chen H, Zhang Y, Thomas HR, Frank MH, He Y, Xia R. TBtools: An Integrative Toolkit Developed for Interactive Analyses of Big Biological Data. Mol Plant. 2020;13:1194-1202.

Crawford NM. Nitrate: nutrient and signal for plant growth. Plant Cell. 1995;7:859-68.

Errebhi M, Wilcox GE. Tomato growth and nutrient uptake pattern as influenced by nitrogen form ratio. J. Plant Nutr. 1990;13:1031-43.

Finn RD, Coggill P, Eberhardt RY, Eddy SR, Mistry J, Mitchell AL, Potter SC, Punta M, Qureshi M, SangradorVegas A, Salazar GA, Tate J, Bateman A. The Pfam protein families database: towards a more sustainable future. Nucleic Acids Res. 2016;44:D279-85.

Forde BG, Clarkson DT. Nitrate and ammonium nutrition of plants: physiological and molecular perspectives. Adv. Bot. Res. 1999;30:1e90.

Gaudinier A, Rodriguez-Medina J, Zhang L, Olson A, Liseron-Monfils C, Bågman AM, Foret J, Abbitt S, Tang M, Li B, Runcie DE, Kliebenstein DJ, Shen B, Frank MJ, Ware D, Brady SM. Transcriptional regulation of nitrogen-associated metabolism and growth. Nature. 2018;563:259-64. 
Gasteiger E, Hoogland C, Gattiker A, Wilkins MR, Appel RD, Bairoch A. Protein Identification and Analysis Tools on the ExPASy Server. In: Walker J.M. (EDS) The Proteomics Protocols Handbook. Springer 2005. pp. 571-607.

Ge M, Wang Y, Liu Y, Jiang L, He B, Ning L, Du H, Lv Y, Zhou L, Lin F, Zhang T, Liang S, Lu H, Zhao H. The NIN-like protein 5 (ZmNLP5) transcription factor is involved in modulating the nitrogen response in maize. Plant J. 2020;102:353-68.

Guan P, Ripoll JJ, Wang R, Vuong L, Bailey-Steinitz LJ, Ye D, Crawford NM. Interacting TCP and NLP transcription factors control plant responses to nitrate availability. Proc Natl Acad Sci U S A. 2017;114:2419-24.

Guan P. Dancing with Hormones: A Current Perspective of Nitrate Signaling and Regulation in Arabidopsis. Front Plant Sci. 2017;8:1697.

Ho CH, Lin SH, Hu HC, Tsay YF. CHL1 functions as a nitrate sensor in plants. Cell. 2009;138:1184-94.

Hooper CM, Castleden IR, Aryamanesh N, Black K, Grasso SV, Millar AH. CropPAL for discovering divergence in protein subcellular location in crops to support strategies for molecular crop breeding. Plant J. 2020;104:812-27.

Jagadhesan B, Sathee L, Meena HS, Jha SK, Chinnusamy V, Kumar A, Kumar S. Genome wide analysis of NLP transcription factors reveals their role in nitrogen stress tolerance of rice. Sci Rep. 2020;10:9368.

Karve R, Suárez-Román F, lyer-Pascuzzi AS. The Transcription Factor NIN-LIKE PROTEIN7 Controls BorderLike Cell Release. Plant Physiol. 2016;171:2101-11.

Konishi M, Yanagisawa S. Arabidopsis NIN-like transcription factors have a central role in nitrate signalling. Nat Commun. 2013;4:1617.

Krzywinski M, Schein J, Birol I, Connors J, Gascoyne R, Horsman D, Jones SJ, Marra MA. Circos: an information aesthetic for comparative genomics. Genome Res. 2009;19:1639-45.

Kumar A, Batra R, Gahlaut V, Gautam T, Kumar S, Sharma M, Tyagi S, Singh KP, Balyan HS, Pandey R, Gupta PK. Genome-wide identification and characterization of gene family for RWP-RK transcription factors in wheat (Triticum aestivum L.). PLoS One. 2018;13:e0208409.

Larkin MA, Blackshields G, Brown NP, Chenna R, McGettigan PA, McWilliam H, Valentin F, Wallace IM, Wilm A, Lopez R, Thompson JD, Gibson TJ, Higgins DG.

Clustal W and Clustal X version 2.0. Bioinformatics. 2007;23:2947-48.

Liu KH, Niu Y, Konishi M, Wu Y, Du H, Sun Chung H, Li L, Boudsocq M, McCormack M, Maekawa S, Ishida T, Zhang C, Shokat K, Yanagisawa S, Sheen J. Discovery of nitrate-CPK-NLP signalling in central nutrientgrowth networks. Nature. 2017;545:311-6. 
Maeda Y, Konishi M, Kiba T, Sakuraba Y, Sawaki N, Kurai T, Ueda Y, Sakakibara H, Yanagisawa S. A NIGT1centred transcriptional cascade regulates nitrate signalling and incorporates phosphorus starvation signals in Arabidopsis. Nat Commun. 2018;9:1376.

Marchive C, Roudier F, Castaings L, Bréhaut V, Blondet E, Colot V, Meyer C, Krapp A. Nuclear retention of the transcription factor NLP7 orchestrates the early response to nitrate in plants. Nat Commun. 2013;4:1713.

Miller AJ, Cramer MD. Root Nitrogen Acquisition and Assimilation. Plant Soil. 2005;274:1-36.

Mu X, Luo J. Evolutionary analyses of NIN-like proteins in plants and their roles in nitrate signaling. Cell Mol Life Sci. 2019;76:3753-64.

Nishida H, Tanaka S, Handa Y, Ito M, Sakamoto Y, Matsunaga S, Betsuyaku S, Miura K, Soyano T, Kawaguchi M, Suzaki T. A NIN-LIKE PROTEIN mediates nitrate-induced control of root nodule symbiosis in Lotus japonicus. Nat Commun. 2018;9:499.

Schauser L, Roussis A, Stiller J, Stougaard J. A plant regulator controlling development of symbiotic root nodules. Nature. 1999;402:191-5.

Schauser L, Wieloch W, Stougaard J. Evolution of NIN-like proteins in Arabidopsis, rice, and Lotus japonicus. J Mol Evol. 2005;60:229-37.

Vidal EA, Alvarez JM, Araus V, Riveras E, Brooks MD, Krouk G, Ruffel S, Lejay L, Crawford NM, Coruzzi GM, Gutiérrez RA. Nitrate in 2020: Thirty Years from Transport to Signaling Networks. Plant Cell. 2020;32:2094-119.

Wang D, Zhang Y, Zhang Z, Zhu J, Yu J. KaKs_Calculator 2.0: a toolkit incorporating gamma-series methods and sliding window strategies. Genomics Proteomics Bioinformatics. 2010;8:77-80.

Wang X, Wang HF, Chen Y, Sun MM, Wang Y, Chen YF. The Transcription Factor NIGT1.2 Modulates Both Phosphate Uptake and Nitrate Influx during Phosphate Starvation in Arabidopsis and Maize. Plant Cell. 2020;32:3519-34.

Wang YH, Garvin DF, Kochian LV. Nitrate-induced genes in tomato roots. Array analysis reveals novel genes that may play a role in nitrogen nutrition. Plant Physiol. 2001;127:345-59.

Wang Z, Zhang L, Sun C, Gu R, Mi G, Yuan L. Phylogenetic, expression and functional characterizations of the maize NLP transcription factor family reveal a role in nitrate assimilation and signaling. Physiol Plant. 2018. doi: 10.1111/ppl.12696. Epub ahead of print. PMID: 29364528.

Xu N, Wang R, Zhao L, Zhang C, Li Z, Lei Z, Liu F, Guan P, Chu Z, Crawford NM, Wang Y. The Arabidopsis NRG2 Protein Mediates Nitrate Signaling and Interacts with and Regulates Key Nitrate Regulators. Plant Cell. 2016;28:485-504. 
Yan D, Easwaran V, Chau V, Okamoto M, lerullo M, Kimura M, Endo A, Yano R, Pasha A, Gong Y, Bi YM, Provart N, Guttman D, Krapp A, Rothstein SJ, Nambara E. NIN-like protein 8 is a master regulator of nitrate-promoted seed germination in Arabidopsis. Nat Commun. 2016;7:13179.

Zou X, Liu MY, Wu WH, Wang Y. Phosphorylation at Ser28 stabilizes the Arabidopsis nitrate transporter NRT2.1 in response to nitrate limitation. J Integr Plant Biol. 2020;62:865-76.

\section{Figures}

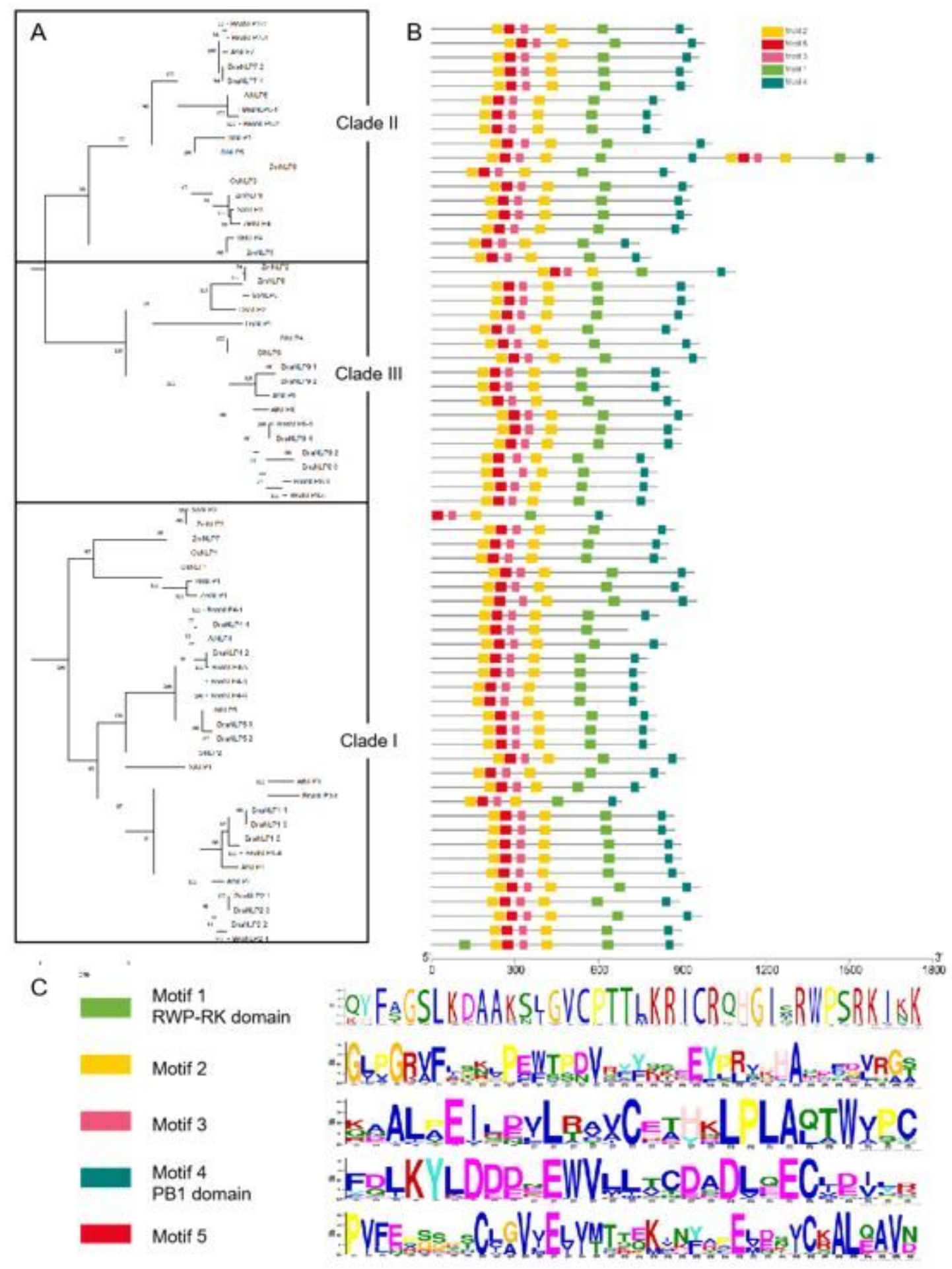


Figure 1

. Phylogenetic tree and conserved motifs of the NLP genes family. (A) A Neighbor-Joining phylogenetic tree of NLPs from tomato (Solanum lycopersicum), Arabidopsis (Arabidopsis thaliana), canola (Brassica napus), rice (Oryza sativa) and maize (Zea mays). All NLP proteins were assigned into three clades. (B) Motifs were identified by MEME. The motifs are displayed in different colors. The scale bar represents 300 amino acids. (C) Sequences of identified motifs including three unknown domains (yellow, pink and red), RWP-RK domain (light green) and PB1 domain (dark green).
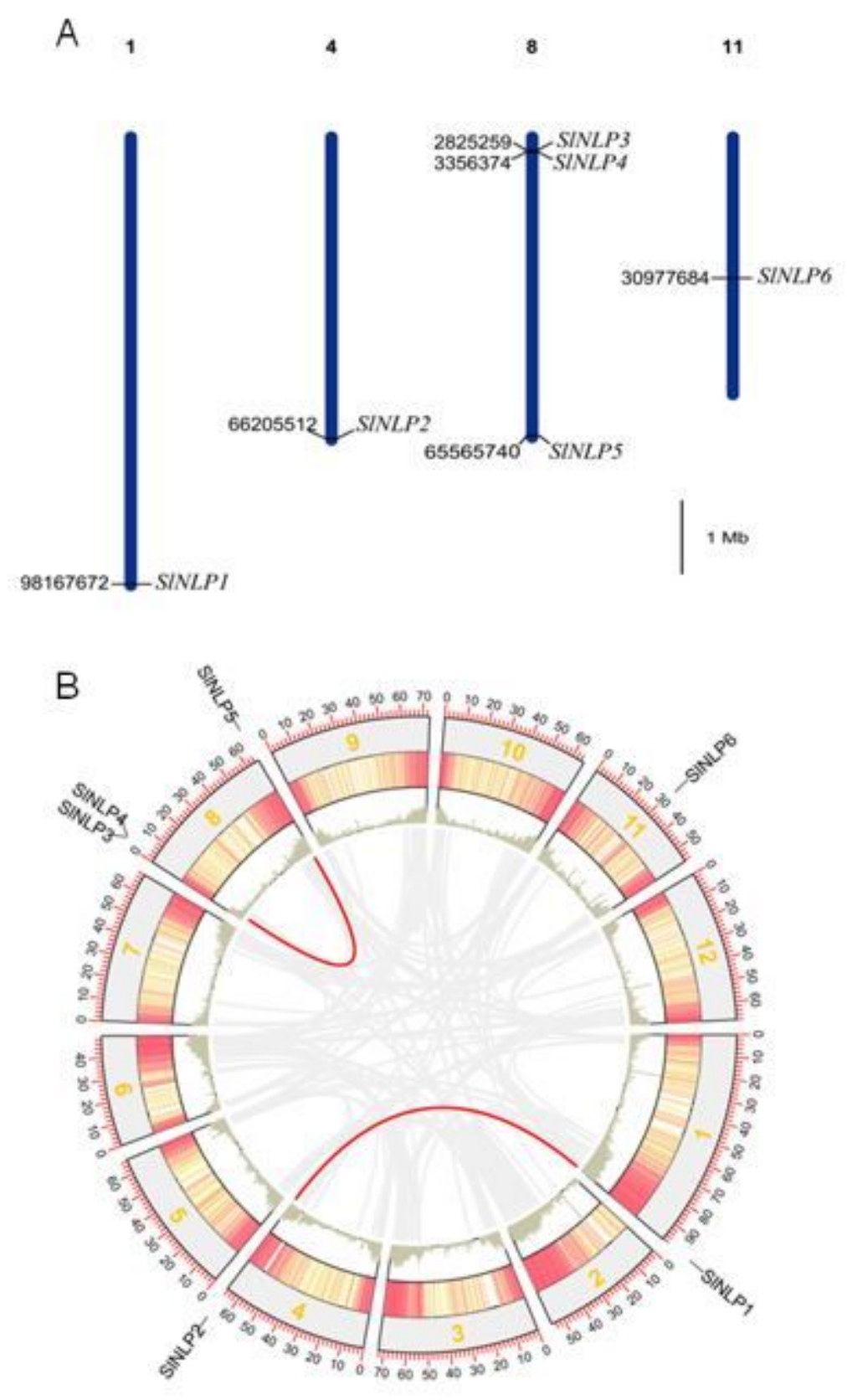

\section{Figure 2}

Chromosomal distribution and interchromosomal relationship of tomato NLP genes. (A) The distributions of SINLP genes on tomato chromosomes 1, 4,8 and 11. The scale bar represents $1 \mathrm{Mb}$. (B) The inner- 
species collinearity of SINLPs. Gray lines indicate all syntenic blocks in tomato genome, and the red lines indicate the duplicated SINLP gene pairs. The number in the grey box area is the chromosome number.

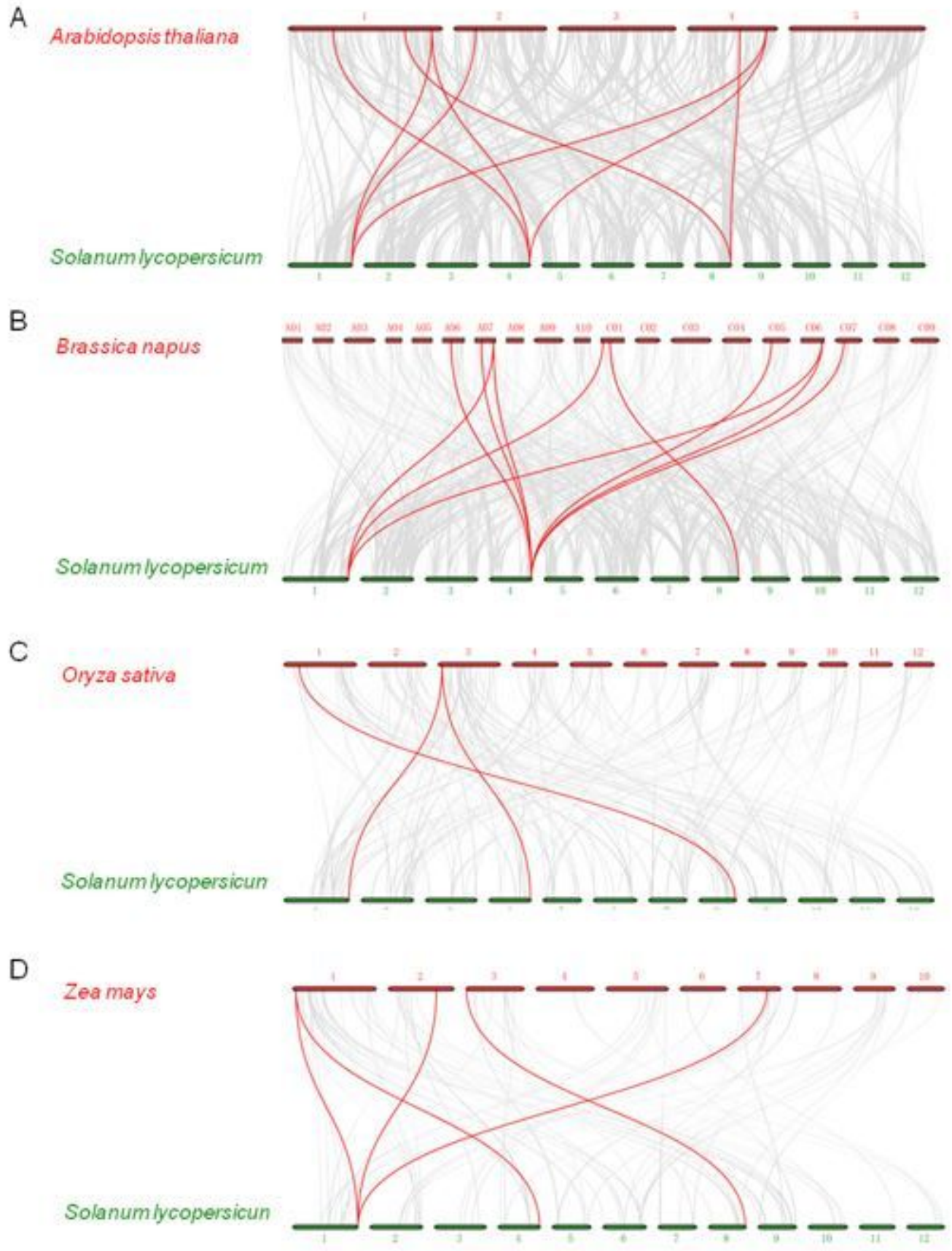

\section{Figure 3}

Syntenic NLP gene pairs between tomoto (Solanum lycopersicum) and four other plant species, including (A) Arabidopsis thaliana; (B) Brassica napus; (C) Oryza sativa; (D) Zea mays. Gray lines indicate all the collinear blocks in genome, while the red lines indicate the syntenic NLP gene pairs. 

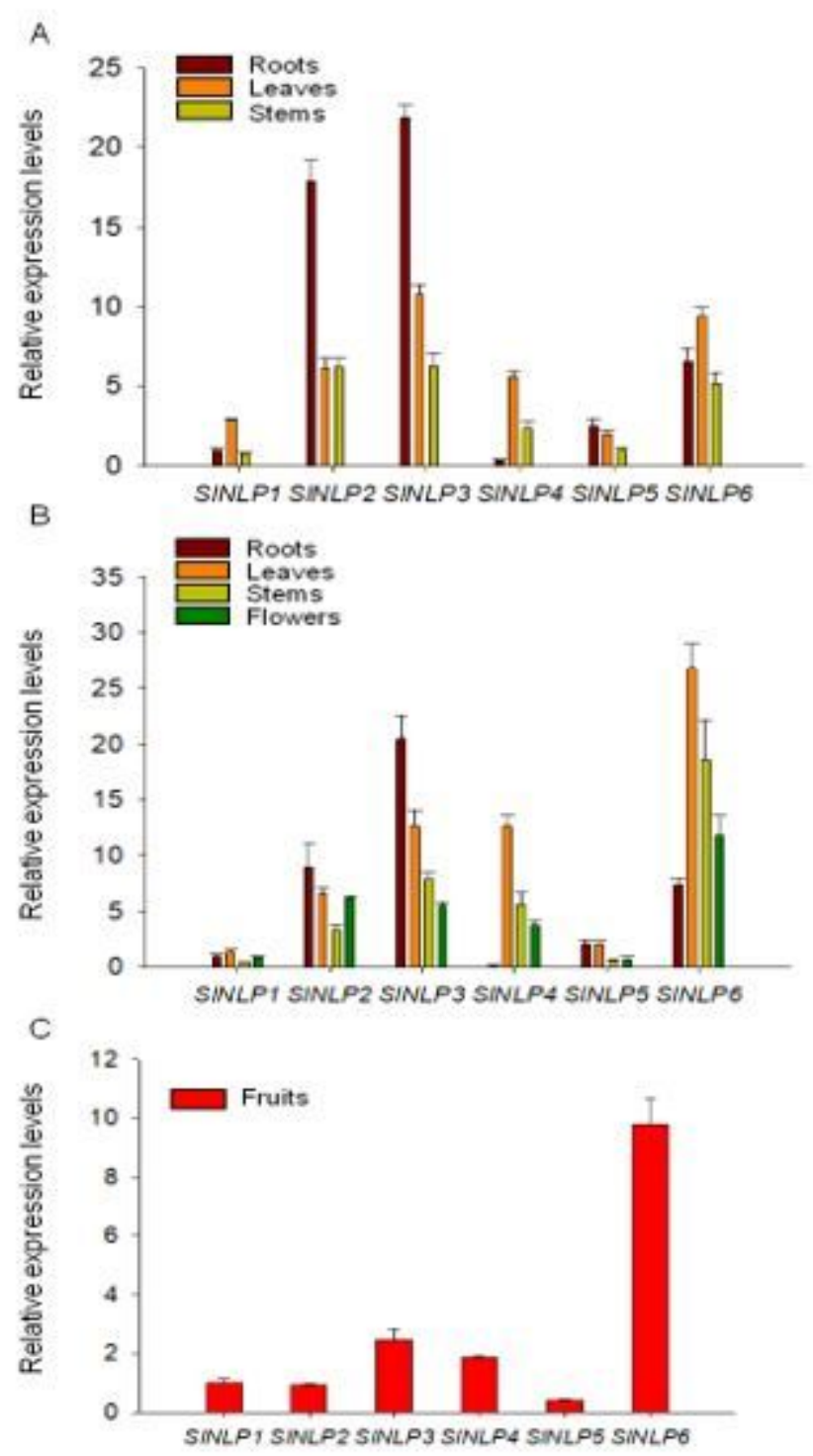

\section{Figure 4}

Tissue-specific expression of SINLPs. (A) Relative expression levels of SINLPs at the seedling stage; (B) Relative expression levels of SINLPs at the flowering stage; (C) Relative expression levels of SINLPs in red fruits. Gene expression levels were normalized to SIEF1a gene and the expression levels of SINLP1 in roots and in fruits were set to 1 respectively. Four biological repeats were analyzed for each samples. 


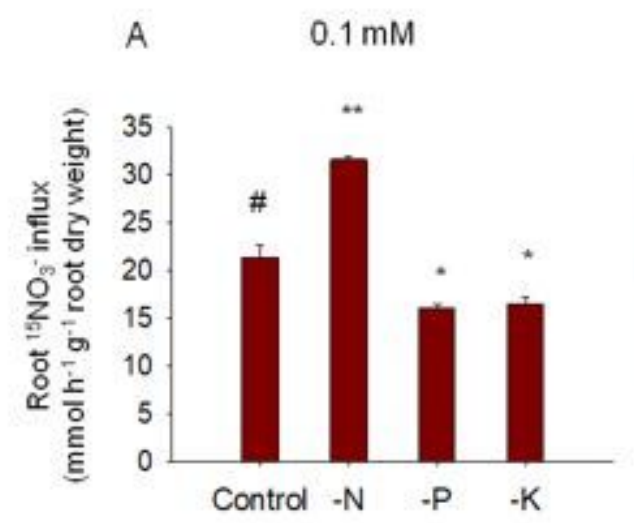

B $\quad 1 \mathrm{mM}$

\section{Figure 5}

Root 15NO3- uptake assay under nutrition deficiency. Seedlings were treated with nitrogen starvation ( $\square$

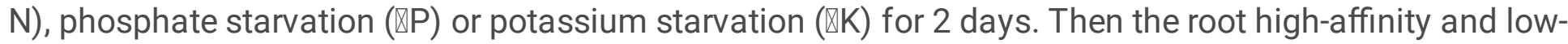
affinity 15NO3- uptake capacity were detected in $0.1 \mathrm{mM}(\mathrm{A})$ or $1 \mathrm{mM}(\mathrm{B}) \mathrm{K} 15 \mathrm{NO} 3$ solution, respectively, for $5 \mathrm{~min}$. Three biological repeats were analyzed for each sample. "\#" represents the control, $\star \star ~ P<0.01$ and $* P<0.05$.
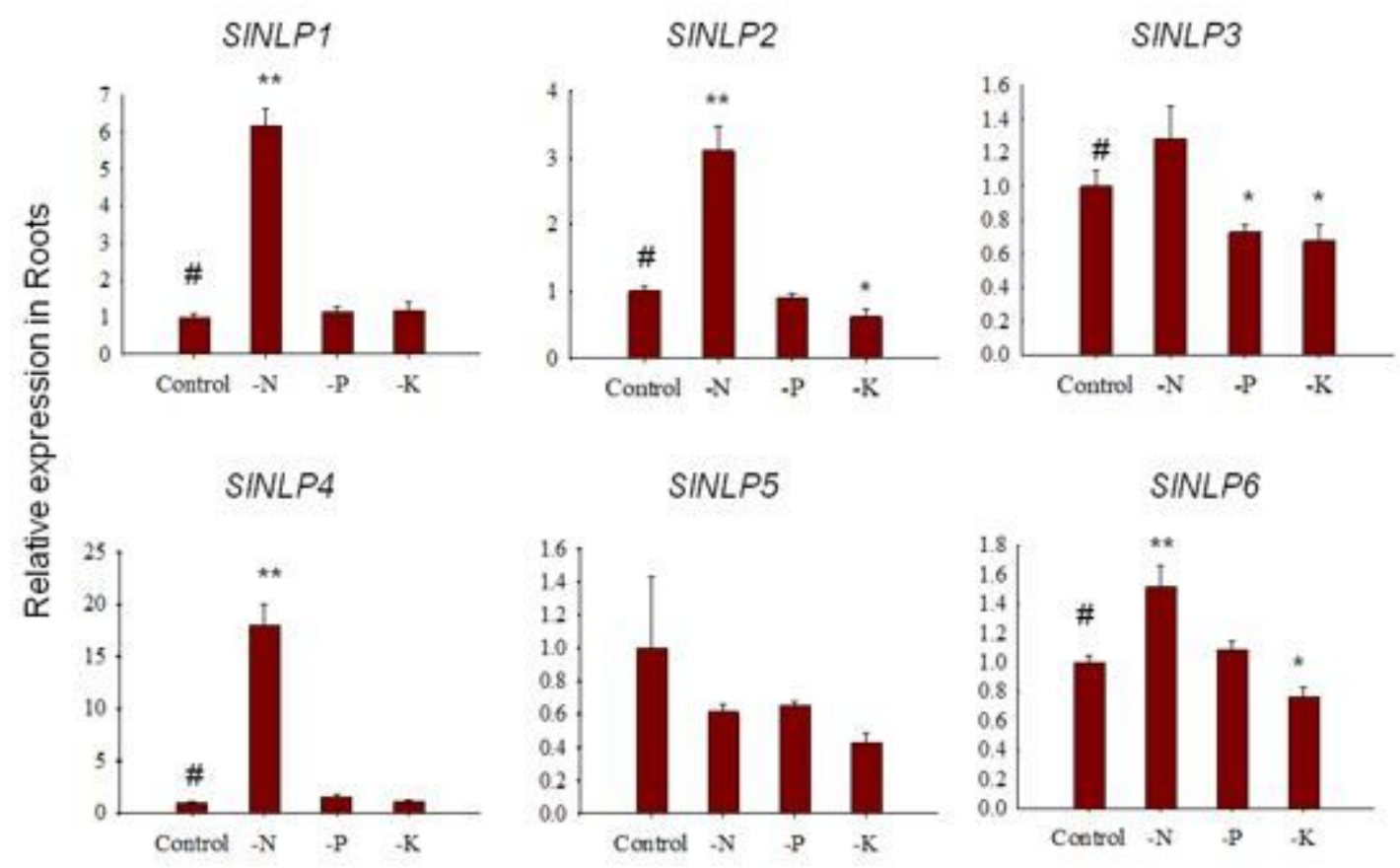

Figure 6

Expression of SINLPs in response to nutrition deficiency. Seedlings were treated with nitrogen starvation

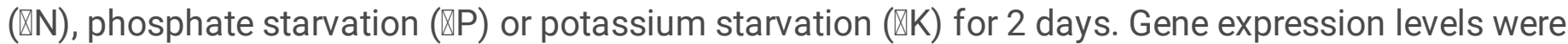


normalized to SIEF1a gene and the expression level in normal hydroponic medium was set to 1 . Four biological repeats were analyzed for each sample. "\#" represents the control, ${ }^{\star *} P<0.01$ and * $P<0.05$.

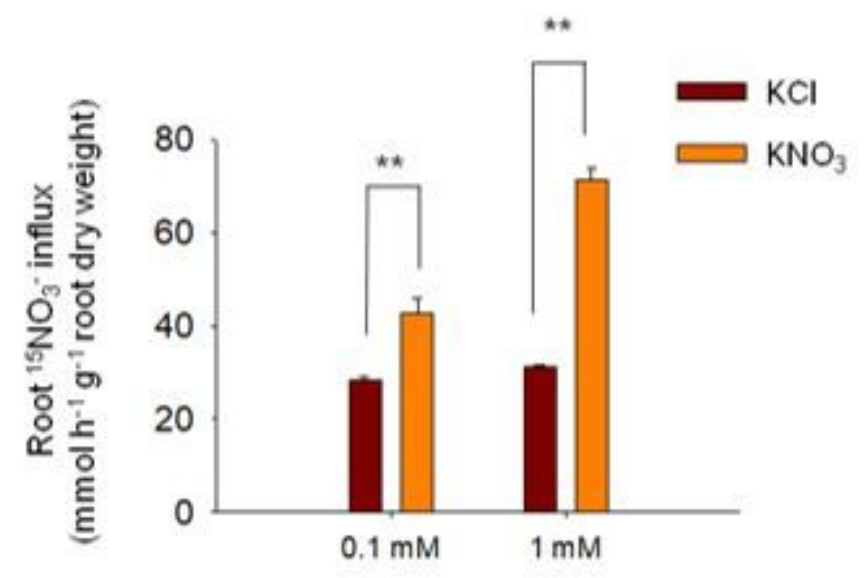

\section{Figure 7}

Root 15NO3- uptake assay after nitrate resupply. Seedlings were nitrogen-starved for 2 days and resupply with $5 \mathrm{mM} \mathrm{KNO3}$ or $5 \mathrm{mM} \mathrm{KCl}$ for 2 hours. Then the root high-affinity and low-affinity 15NO3uptake capacity were detected in $0.1 \mathrm{mM}$ or $1 \mathrm{mM} \mathrm{K15NO3}$ solution, respectively, for $5 \mathrm{~min}$. Three biological repeats were analyzed for each sample. "\#" represents the control, $* \star P<0.01$ and * $P<0.05$.

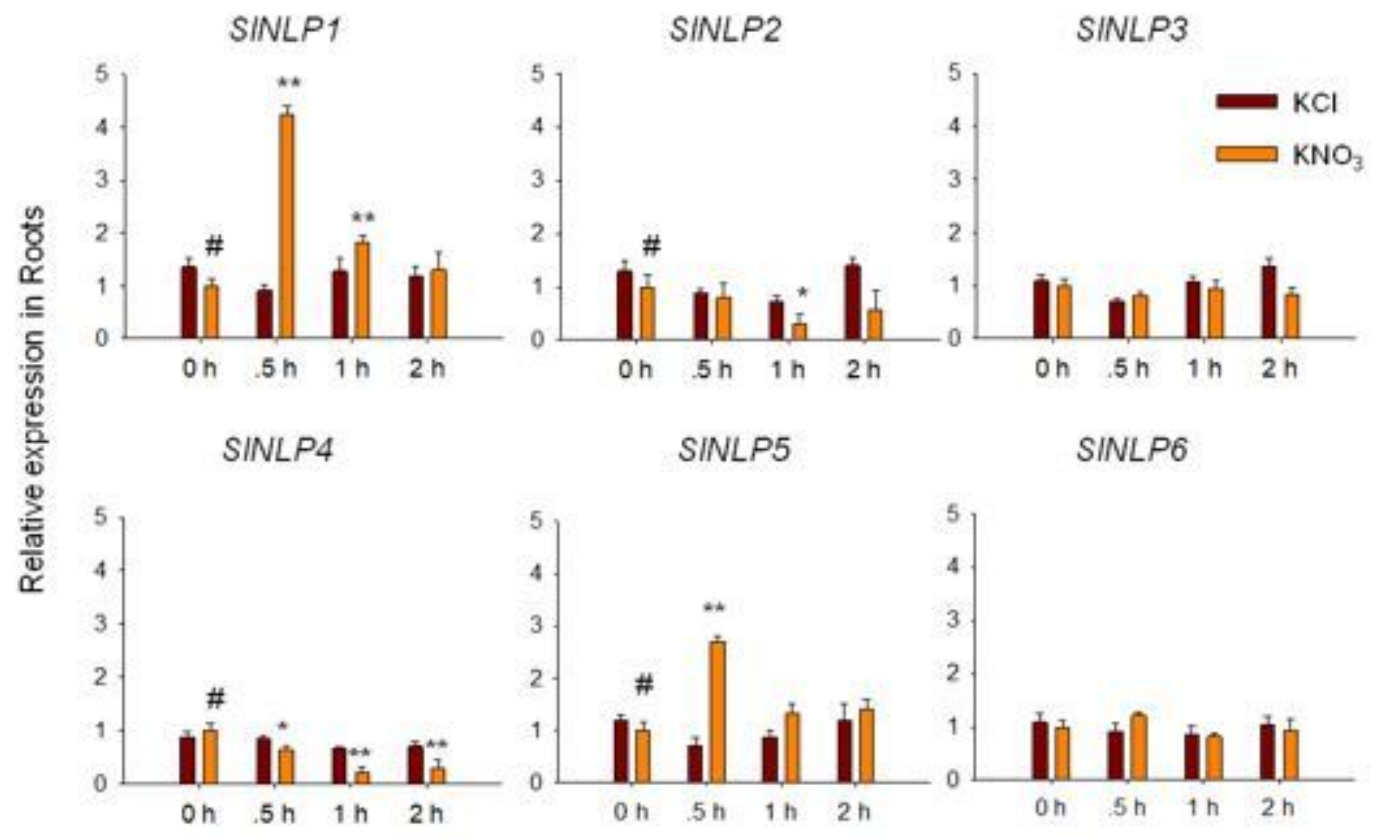

\section{Figure 8}

Nitrate-dependent expression of SINLPs. Seedlings were nitrogen-starved for 2 days and resupply with 5 $\mathrm{mM}$ nitrate or $5 \mathrm{mM} \mathrm{KCl}$ as control for 2 hours. Total RNAs were extracted from roots at $0,0.5,1,2$ hours 
after treatment and subjected to qRT-PCR analysis. Gene expression levels were normalized to SIEF1a gene and the expression level in samples at $0 \mathrm{~h}$ in $5 \mathrm{mM} \mathrm{KCl}$ medium was set to 1 . Four biological repeats were analyzed for each sample. "\#" represents the control, ** $\mathrm{P}<0.01$ and * $\mathrm{P}<0.05$.

\section{Supplementary Files}

This is a list of supplementary files associated with this preprint. Click to download.

- SupplementaryTable1.NLPgenes.xlsx

- SupplementaryTable2.Onetooneorthologousrelationships.xls

- SupplementaryTable3.PrimersusedinqRTPCR.xlsx 